\title{
Spectrophotometric measurement of proteoglycans in osteoarthritic synovial fluid
}

\author{
G J CARROLL \\ From the Strangeways Research Laboratory, Worts Causeway, Cambridge
}

SUMmARY Cartilage glycosaminoglycans (GAGs) were measured by a spectrophotometric assay in synovial fluid obtained from 30 normal bovine hock joints and 15 osteoarthritic human knee joints. Results were compared with those obtained by radioimmunoassay (RIA). The spectrophotometric method (dimethylmethylene blue (DMB) assay) was found to be simple, safe, and sufficiently reproducible to be of potential value for serial measurement of sulphated GAGs in arthritic joint fluids. The nature of the proteoglycans present in normal bovine and osteoarthritic human synovial fluid was examined by gel chromatography. Whereas normal bovine synovial fluid contained only small molecular weight proteoglycans, osteoarthritic human synovial fluid contained aggregated proteoglycans and predominantly high molecular weight proteoglycan subunits.

Key words: glycosaminoglycans, radioimmunoassay, normal bovine synovial fluid, gel filtration chromatography.

The state of the articular cartilage is of major interest to the clinician evaluating patients with arthritis. Physical examination is often inadequate in this respect and general laboratory investigations are not helpful. Joint radiographs can be informative, but have limitations. These shortcomings have stimulated investigators to develop methods for measuring cartilage proteoglycans in synovial fluid. Gysen and Franchimont have developed a radioimmunoassay (RIA) for this purpose, ${ }^{1}$ and Roughley et al have developed a similar technique. ${ }^{2}$ Recently, Saxne et al reported the use of an enzyme linked immunosorbent assay (ELISA) to measure proteoglycans in synovial fluids from patients with various inflammatory joint diseases. ${ }^{3}$ The same authors have subsequently used an ELISA to evaluate the effects of corticosteroids on cartilage metabolism. ${ }^{4}$

Glycosaminoglycan assays have been used extensively in the past to measure proteoglycans in vitro, but with the exception of urine they have proved unsatisfactory for measurement of proteoglycans in biological fluids, mainly because they are subject to interference by other polyanions. ${ }^{56}$ In particular, such assays have been unsuitable for the determina-

Accepted for publication 29 October 1986.

Correspondence to Dr G J Carroll. Department of Rheumatic Diseases, Royal Perth Rehabilitation Hospital. Shenton Park 60)(8. Western Australia. tion of proteoglycan concentrations in synovial fluid where there is a large molar excess of hyaluronic acid. By modifying the $\mathrm{pH}$ and $\mathrm{NaCl}$ concentration of the DMB dye reagent. Farndale et al have improved the selectivity of the DMB spectrophotometric microassay for sulphated glycosaminoglycans. ${ }^{78}$ In this study the modified DMB assay has been used to determine the concentration of sulphated GAGs in synovial fluid, and the results have been compared with proteoglycan concentrations determined by RIA.

\section{Materials and methods}

MATERIALS

$\mathrm{Na}^{125} \mathrm{I}$ (specific activity $625 \mathrm{MBq} / \mu \mathrm{g}$ of iodine) was purchased from Amersham International, Amersham, UK. Chondroitin ABC lyase and Staphylococcus protein $A$ were obtained from Miles Laboratories, Slough, UK. Sepharose CL-2B was purchased from Pharmacia Fine Chemicals, Uppsala, Sweden. $N$-Acetylcysteine, papain, iodoacetic acid, 1,10-phenanthroline, and phenylmethylsulphonyl fluoride were all obtained from Sigma Chemical Co, London, UK. Chondroitin sulphate was from KochLight Laboratories Ltd, Haverhill, UK. 1.9Dimethylmethylene blue was purchased from Serva Feinbiochemica, Heidelberg. FRG. All other chemicals were AR grade. 
Bovine synovial fluid was obtained from the hock joints of freshly slaughtered cows. Human synovial fluid was obtained from patients with osteoarthritis who at the time of outpatient review were deemed to warrant joint aspiration. Fluids were collected into plastic vials, centrifuged at $1000 \mathrm{~g}$ for $10 \mathrm{~min}$ to remove cells and debris, and stored in aliquots at $-70^{\circ} \mathrm{C}$ until assayed.

Radioimmunoassays were performed directly on diluted specimens of synovial fluid using the method described by Christner et al. ${ }^{9}$ Rabbit antiserum (R110) directed against bovine proteoglycan A1D1 was a generous gift from A R Poole.

\section{DIMETHYLMETHYLENE BLUE ASSAY FOR G A G}

The DMB assay was adapted from the method of Farndale et al and is described in detail elsewhere. ${ }^{78}$ Samples of synovial fluid $(500 \mu \mathrm{l})$ were dispensed into plastic vials with a $1 \mathrm{ml}$ Gilson pipette and diluted to $5 \mathrm{ml}$ with $50 \mathrm{mM}$ phosphate buffered saline, $\mathrm{pH} 7 \cdot 0$. Special care was taken to wash out the pipette tip with the diluent in order to minimise drainage error. Aliquots $(100 \mu \mathrm{l})$ were mixed by repeated inversion and transferred in duplicate to polystyrene tubes. A further $100 \mu$ l of the same buffer containing $\mathrm{N}$-acetylcysteine (final concentration $2 \mathrm{mmol} / \mathrm{l}$ ) and papain 0.13 units was added, and the tubes were mixed and capped. The samples wete then incubated at $65^{\circ} \mathrm{C}$ for two hours. After diges tion the papain was inactivated with iodoacetic acid (final concentration $4 \mathrm{mmol} / \mathrm{l}$ ) and the $\mathrm{NaCl}$ concer tration of the digest was adjusted to approximate $0.5 \mathrm{~mol} / \mathrm{l}$ in a final volume of $250 \mu \mathrm{l}$.

Dimethylmethylene blue dye reagent $(2.5 \mathrm{ml})$ wæ then added and the absorbance at $525 \mathrm{~nm}$ was read after $15 \mathrm{~s}$ in a Cecil CE 292 digital ultraviolet spectrophotometer. The DMB reagent was prepared by adding $3.04 \mathrm{~g}$ of glycine, $2.37 \mathrm{~g}$ of NaCd and $16 \mathrm{mg}$ of 1,9-dimethylmethylene blue to 1 lit of deionized water. The $\mathrm{pH}$ was adjusted to 3.0 wi $\overline{\text { }}$ hydrochloric acid and the reagent was stored in brown bottle.

The DMB assay was calibrated with shark chow droitin sulphate and suitable solvent blanks.

\section{GEL CHROMATOGRAPHY}

The hydrodynamic size distribution of the prote glycans in normal bovine and osteoarthritic humam synovial fluids was determined by gel chromate $\vec{e}$ graphy on columns $(67 \times 1 \mathrm{~cm})$ of Sepharose CL-2B: Samples consisting of $1 \mathrm{ml}$ of synovial fluid and the proteinase inhibitors, 1,10 -phenanthroline $(1 \mathrm{mM}$ iodoacetic acid $(1 \mathrm{mM})$, and phenylmethylsulphon fluoride $(1 \mathrm{mM})$ were applied to the column and chromatographed at $22^{\circ} \mathrm{C}$ and $6 \mathrm{ml} / \mathrm{h}$. Fractions

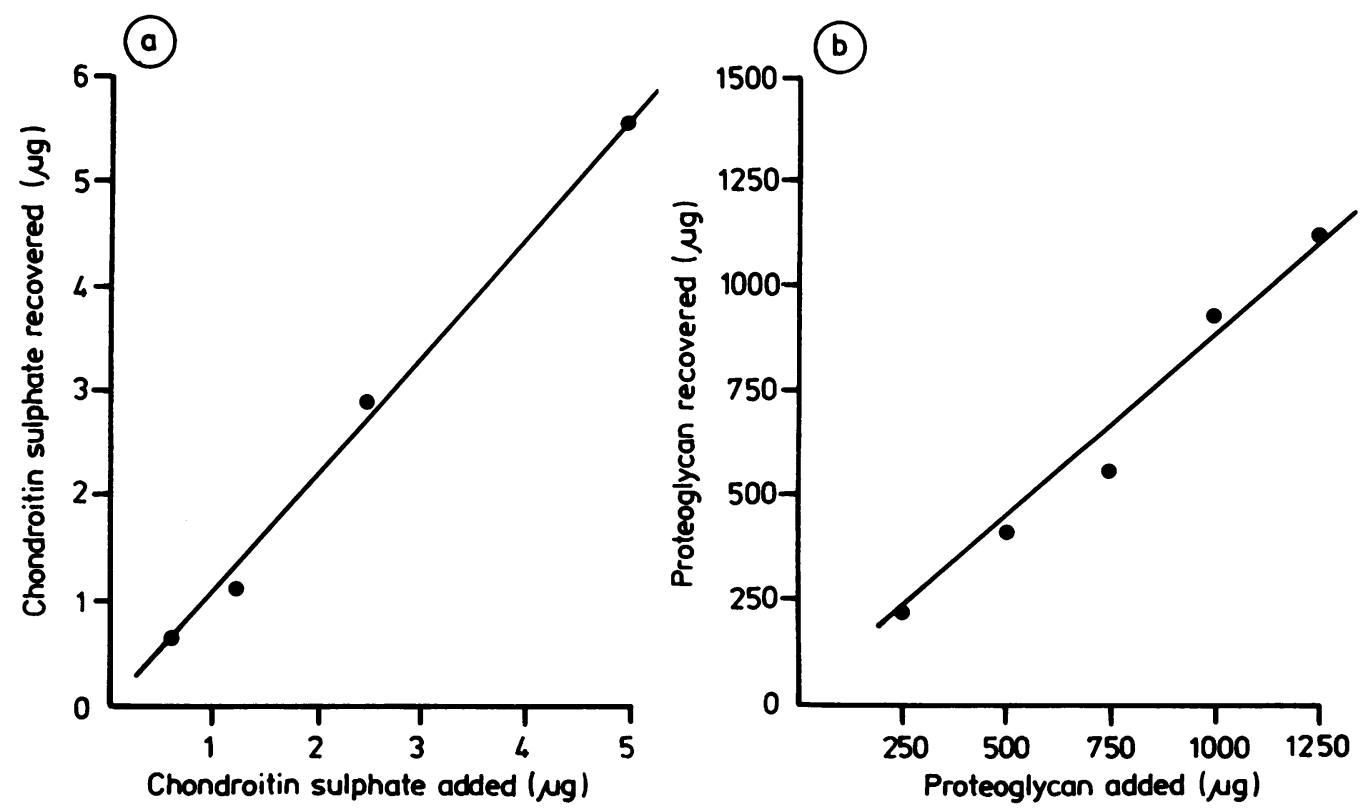

Fig. 1 (a) Chondroitin sulphate was added to osteoarthritic synovial fluid and the recovery determined by the modified $D M B$ assay. (b) High molecular weight proteoglycan subunit was added to osteoarthritic synovial fluid and the recovery determined by RIA. 
$(500 \mu \mathrm{l})$ were collected and aliquots were assayed in duplicate by the spectrophotometric and radioimmunoassay procedures described. The quantity of proteoglycans recovered after gel chromatography $(89-97 \%, n=3)$ was consistent with that estimated in the starting material by the DMB assay and RIA.

\section{Results}

ASSAY PERFORMANCE AND PROTEOGLYCAN RE C OVER'Y

Both assays were sufficiently sensitive to determine proteoglycan or GAG concentrations, or both, in synovial fluid and chromatographic fractions thereof. The sensitivity in synovial fluid was $10 \mu \mathrm{g} / \mathrm{ml}$ for the RIA and $20 \mu \mathrm{g} / \mathrm{ml}$ for the DMB assay. In synovial fluid the within assay coefficient of variation was $5.3 \% \quad(n=10)$ for the DMB assay and $13.8 \%(n=5)$ for the RIA. The between assay coefficient of variation was $11.2 \%(n=3)$ for the DMB assay and $29 \cdot 2 \%(n=3)$ for the RIA. Thus the DMB assay was more reproducible and the RIA twice as sensitive.

Increasing quantities of proteoglycan were added to undiluted synovial fluid, and the recovery determined by each assay procedure is shown in Fig. 1 . Similar recovery was obtained with both methods.

\section{BOVINE SYNOVIAL FLUID PROTEOGLYCAN ASS A Y S}

With the DMB assay the mean concentration of sulphated GAGs was $155 \mu \mathrm{g} / \mathrm{ml}$ of synovial fluid (standard error (SE) $11 \mu \mathrm{g} / \mathrm{ml}, \mathrm{n}=30$ ). With the RIA the mean concentration of proteoglycan was 183 $\mu \mathrm{g} / \mathrm{ml}$ of synovial fluid (SE $20 \mu \mathrm{g} / \mathrm{ml}, \mathrm{n}=30$ ). The correlation coefficient was $0.60(\mathrm{p}<0.001$, Student's $t$ test), which indicates satisfactory agreement between the two methods.

HUMAN SYNOVIAL FLUID PROTEOGLYCAN A S S A Y S

Aliquots of osteoarthritic synovial fluid were assayed by both methods on three occasions. No drift was evident with storage. Mean values were determined from the three assays and compared. With the DMB assay the mean concentration of sulphated GAGs was $142 \mu \mathrm{g} / \mathrm{ml}$ of synovial fluid (SE $13 \mu \mathrm{g} / \mathrm{ml}, \mathrm{n}=15$ ). With the RIA the mean concentration of proteoglycans was $122 \mu \mathrm{g} / \mathrm{ml}$ of synovial fluid (SE $10 \mu \mathrm{g} / \mathrm{ml}, \mathrm{n}=15$ ). The scatter of the results obtained with each method is shown in Fig. 2. The correlation coefficient was $0.51(0 \cdot 10>p>0 \cdot 05$, Student's $t$ test).

SIZE DISTRIBUTION OF THE

PROTEOGLYCANS IN SYNOVIAL FLUID

Normal bovine synovial fluids were found to contain mainly small proteoglycan molecules (Fig. 3a). In contrast, osteoarthritic human synovial fluids contained a significant proportion of aggregated proteoglycan in addition to monomeric proteoglycans of diverse molecular weight (Fig. 3b). The difference in the position of the peaks indicates that the proteoglycans of varying hydrodynamic size differ with respect to their sulphated GAG content. In normal bovine synovial fluid the proteoglycans of higher molecular weight (corresponding to effluent volumes $38-48 \mathrm{ml}$ ) are richer in sulphated GAG than those of lower molecular weight (corresponding to effluent volumes $49-58 \mathrm{ml}$ ). In human synovial fluid from patients with osteoarthritis it can be seen from the data in Fig. $3 b$ that the aggregated proteoglycans (corresponding to effluent volumes 20-25 ml) have a lower sulphated GAG content than the large and small proteoglycan monomers. The presence of proteoglycan aggregates in the human synovial fluid indicates that some of the proteoglycan molecules are bound to hyaluronic

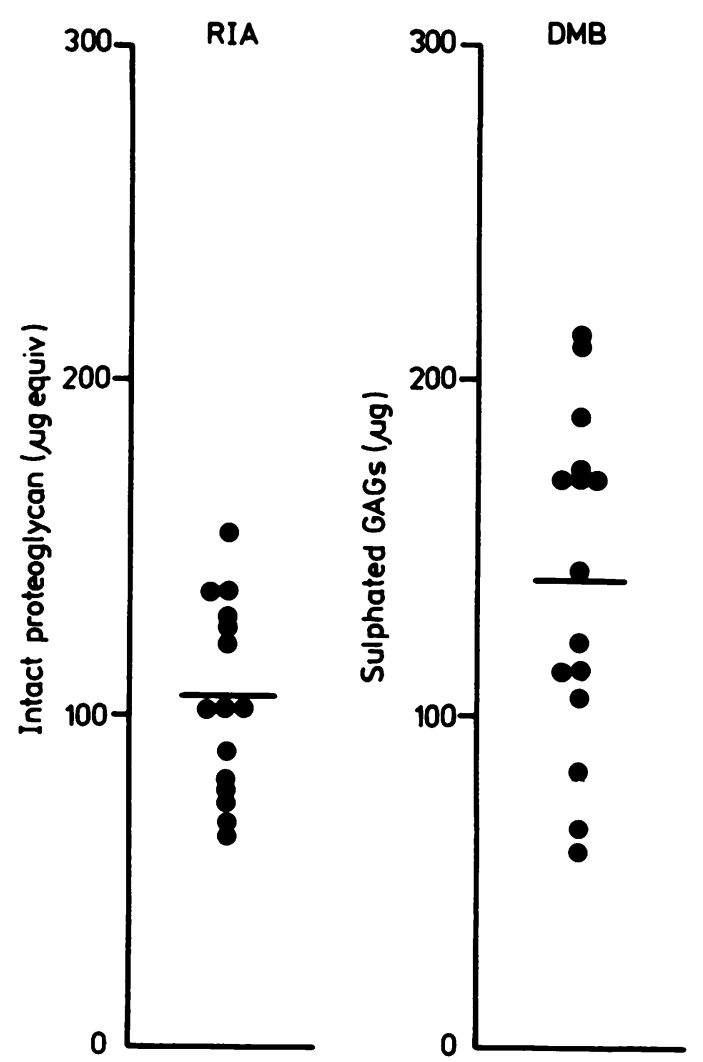

Fig. 2 The distribution of $G A G$ concentrations in 15 osteoarthritic knee joint synovial fluids. 


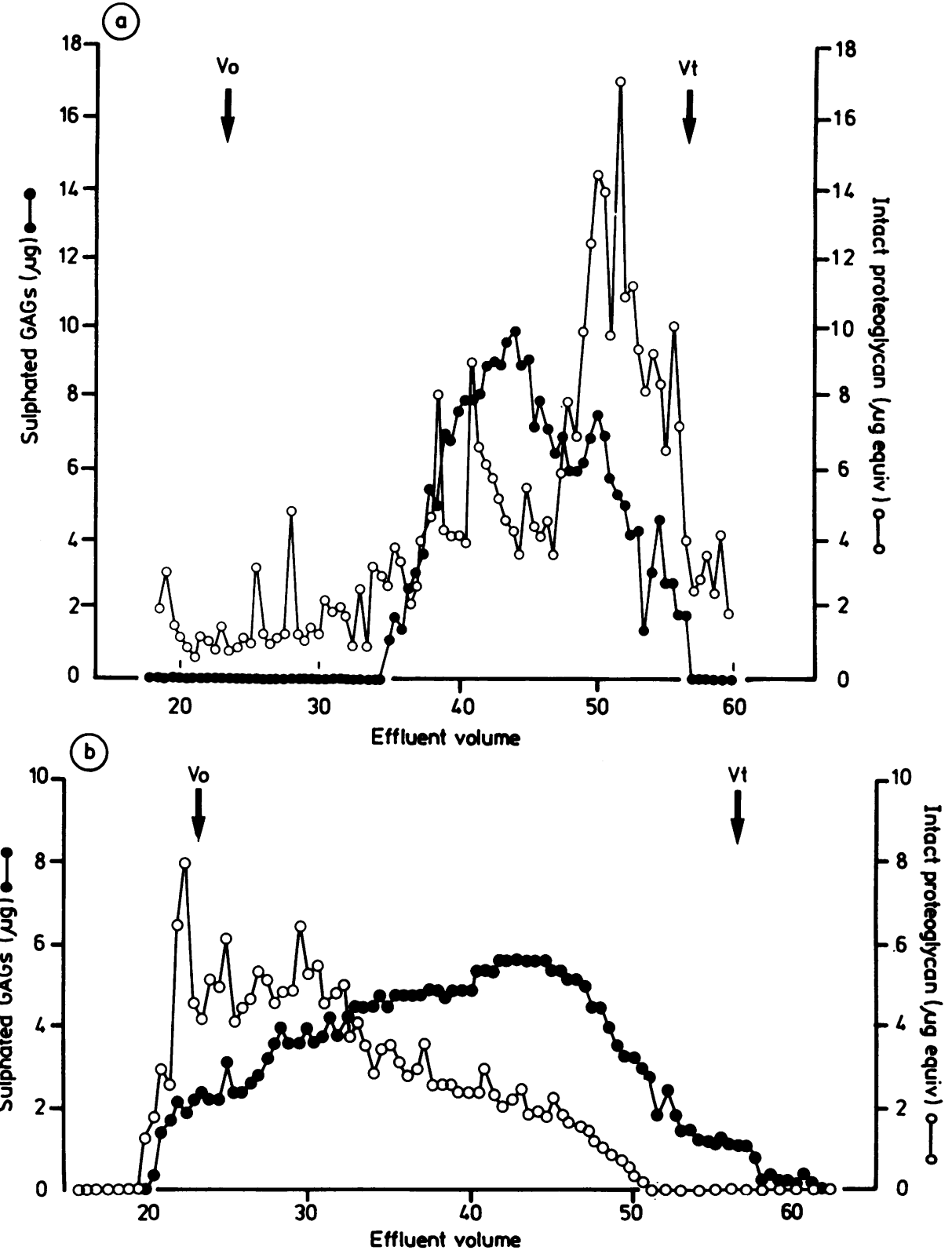

Fig. 3 Size distribution of the cartilage degradation products in (a) normal bovine synovial fluid and (b) osteoarthritic human knee joint synovial fluid.

acid and suggests that these molecules still possess a functionally intact binding domain.

\section{Discussion}

The DMB assay and RIA were both found to be sufficiently sensitive for measurement of cartilage degradation products in synovial fluid. Samples of

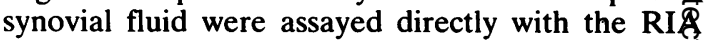
whereas previous digestion with papain was nece sary for the DMB assay. The reproducibility of the assays was found to be satisfactory for the DMB 
assay, but not the RIA. The results obtained with the RIA, however, are consistent with those reported by Saxne et al and also Gysen et al. ${ }^{3410}$

The DMB assay has several advantages over RIAs. It does not require radioisotopes and is therefore safer. The required reagents are readily available and inexpensive. It also has a theoretical advantage since it measures the glycosaminoglycan moiety of proteoglycans, and the polysaccharides are less likely to be degraded than the core protein component. Moreover, since it is a chemical method highly comparable results should be obtained when homogeneous groups of patients are studied in different centres.

The reason for the poor correlation between the DMB assay and the RIA is not entirely clear. The poor reproducibility of the RIA may be relevant. Two other possibilities need to be considered. Proteoglycans from articular cartilage contain approximately equal proportions of chondroitin sulphate and keratan sulphate and have $30-50 \%$ protein. ${ }^{11}$ Use of chondroitin sulphate as standard for the DMB assay is likely to underestimate the total GAG content since chondroitin sulphate and keratan sulphate differ in their reactivity with DMB ${ }^{8}$ It is also possible that the antiserum used in the RIA does not recognise all of the proteoglycan present in synovial fluid either by virtue of its nature or because some of the proteoglycan molecules in synovial fluid have lost their recognition sites.

Gel chromatography of normal bovine synovial fluid showed the presence of predominantly small proteoglycan molecules. No proteoglycan aggregates were detected. These findings are unlikely to be due to proteolysis during storage or chromatography since consistent results were obtained when fresh specimens were chromatographed immediately in the presence of various proteinase inhibitors. The remote possibility of rapid postmortem catabolism, however, cannot be excluded. Whether the size distribution of the proteoglycans in normal human synovial fluid is similar is not yet known.

In contrast, a significant proportion of the proteoglycans present in osteoarthritic synovial fluid were found to be aggregated and most of the monomers present were of higher molecular weight. This distribution is in agreement with that found by Gysen et al and closely resembles the size distribution of the proteoglycans which can be extracted from human articular cartilage with high concentrations of salt. ${ }^{10}$ Although the mechanism governing the release of proteoglycans from osteoarthritic cartilage is still a matter of conjecture, the presence in the synovial fluid of proteoglycans with a functionally intact hyaluronic acid binding region suggests that at least a subset of proteoglycans may be released from cartilage without enzymatic cleavage of this region.

In summary, the modified DMB assay has been shown to be suitable for measuring glycosaminoglycans in synovial fluid. In addition to being sufficiently sensitive, specific, and reproducible the method is simple, safe, and inexpensive. The DMB assay expands the range of methods now available for measuring cartilage degradation products in synovial fluid. These techniques are likely to prove increasingly useful for monitoring disease progression and the effects of various therapeutic strategies. In combination with other lines of inquiry they are also likely to provide further insight into the mechanisms responsible for cartilage resorption in arthritic diseases.

I thank the staff of the rheumatology research unit at Addenbrookes Hospital for the generous provision of human synovial fluid and Dr A R Poole who kindly supplied the materials for the radioimmunoassay. I am grateful to Drs D J Buttle, R W Farndale, and $\mathrm{J} T$ Dingle for helpful advice and enthusiastic support. I also thank Mr Christopher Green who prepared the illustrations and Ms Jane Mead for her secretarial services. This project was supported by the Arthritis and Rheumatism Council of Great Britain and was carried out while the author was a recipient of a W A and M G Saw Medical Research Fellowship from the University of Western Australia.

\section{References}

1 Gysen P. Franchimont P. Radioimmunoassay of proteoglycans. J Immunoassay 1984: 5: 221-43.

2 Roughley P J. White R J, Poole A R. Identification of a hyaluronic acid-binding protein that interferes with the preparation of high-buoyant density proteoglycan aggregates from adult human articular cartilage. Biochem $J$ 1985; 231: 129-38.

3 Saxne T, Wollheim F A, Heinegård D, Pettersson H. Difference in cartilage proteoglycan level in synovial fluid in early rheumatoid arthritis and reactive arthritis. Lancet 1985; ii: $127-8$.

4 Saxne T, Heinegård D. Wollheim F A. Therapeutic effects on cartilage metabolism in arthritis as measured by release of proteoglycan structures into the synovial fluid. Ann Rheum Dis 1986; 45: 491-7.

5 Humbel R. Etringer S. A colorimetric method for the determination of sulfated glycosaminoglycans. Rev Roum Biochim 1974; 11: 21-4.

6 Saklatvala J, Curry V A, Sarsfield S J. Purification to homogeneity of pig leukocyte catabolin, a protein that causes cartilage resorption in vitro. Biochem $J$ 1984; 224: 421-6.

7 Farndale R W. Sayers C A. Barrett A J. A direct spectrophotometric microassay for sulphated glycosaminoglycans in cartilage cultures. Connect Tissue Res 1982; 9: 247-8.

8 Farndale R W, Buttle D J, Barrett A J. Improved quantitation and discrimination of sulphated glycosamino glycans by use of dimethylmethylene bluc. Biochem Biophys Acta 1986; 883: 173-7.

9 Christner J E, Caterson B. Baker J R. Immunological determinants of proteoglycans. J Biol Chem 1980; 225: 7102-5.

10 Gysen P. Malaise M. Gaspar S. Franchimont P. Measurement of proteoglycans, elastase, collagenase and protein in synovial fluid in inflammatory and degenerative arthropathies. Clin Rheumatol 1984: 4: 39-50.

11 Bayliss M T. Ali S Y. Age-related changes in the composition and structure of human articular-cartilage proteoglycans. Biochem J 1978; 176: 683-93. 